\title{
Lexis
}

Journal in English Lexicology

$17 \mid 2021$

Humor, creativity and lexical creation

\section{Incongruous Names: the Humorous Coinage and Use of Proper Names}

\section{Manon Philippe}

\section{OpenEdition}

1 Journals

\section{Electronic version}

URL: https://journals.openedition.org/lexis/5204

DOI: $10.4000 /$ lexis.5204

ISSN: 1951-6215

\section{Publisher}

Université Jean Moulin - Lyon 3

\section{Electronic reference}

Manon Philippe, "Incongruous Names: the Humorous Coinage and Use of Proper Names", Lexis [Online], 17 | 2021, Online since 15 August 2021, connection on 20 August 2021. URL: http:// journals.openedition.org/lexis/5204 ; DOI: https://doi.org/10.4000/lexis.5204

This text was automatically generated on 20 August 2021

\section{(c) (i) (9)}

Lexis is licensed under a Creative Commons Attribution-NonCommercial-NoDerivatives 4.0 International License. 


\title{
Incongruous Names: the Humorous Coinage and Use of Proper Names
}

\author{
Manon Philippe
}

\section{Introduction}

1 As humorous devices go, proper names deserve more attention. If fictional proper names, created for the purpose of a specific narrative, often have semantic and literary motivations that can be humorous, non-fictional proper names of people, places, organizations, books or TV shows/songs and so on, will also have the potential to be used, echoed or diverted in a playful way, relying on the reader's encyclopedic knowledge of the referents and their linguistic proficiency. In that respect, proper names fit into the humorous devices that involve "a form of [mental] play comprising a social context, a cognitive process and an emotional response" as well as "expressive components" (Martin [2010: 83, 193]). More specifically, humor lies in the playful mismatch between what is expected of a proper name as a lexical unit at the level of language and what is being done with the proper name in actual speech.

Presented this way, it seems that proper names illustrate a special kind of humor that pertains to the general framework of humor as incongruity (Attardo [2014]), as confirmed by research on opposing semantic scripts specific to proper names (Rutkowski [2016]). However, I would argue that humorous proper names are not just reduced to expressing these contrasting semantic scripts and that their very linguistic (lexical-ized) nature is a humorous powerhouse. In fact, proper names may very well be specialized in signaling metalinguistic humor, in the sense that humorous effects derive either from the obvious transgressions of the linguistic constraints usually associated with proper names as a nominal unit or from the direct consequences of their nominal status. In other words, proper names may be used or coined humorously because they are incongruous morphosyntactic units to begin with. This means that semantic incongruity, i.e. the main component of the incongruity theory, cannot be the only ingredient of humorous coinage and use of proper names. Which is why I turned 
to one of the roots of the incongruity theory to find other parameters that could explain why proper names express humor the way they do.

It seems that proper names inherently bear something of the Bergsonian characterization of humor (Bergson [1911]). Bergson's theory of humor rests upon the idea that humor forces the audience to notice a form of rigidity, or rigidification, in an otherwise fluid pattern. Distractions operate a digression, or a diversion, from the "normal" way society, life, a person or language is supposed to behave. They do so by directing the audience's attention toward the repetition, the exaggeration and especially the rigidification of a particular feature. Unnoticed, this feature would not be humorous; noticed, because exaggerated and/or momentarily frozen, it becomes a source of humor. I would like to show how proper names express humor through their inherent, constructed lexical rigidity: due to their status as attention-seeking, semantically-constrained lexicalized nominals, they are lexical distractions that may be activated to go from truly rigid to truly humorous in context.

4 The paper is organized as follows: Section 1 will present an overview of some theoretical descriptions of humor and connect it with proper names, finishing with a brief presentation of Bergson's theory of rigidity and distraction and how it can aptly be used to describe humorous proper names in English. Section 2 will summarize the basic properties associated with proper names, some of which may be used to achieve humor, before detailing different stages at which proper names may be distractions. Humor in proper names derives from their lexicalized status which both freezes their form but also their meaning or reference: humorously used proper names draw on their inherent rigidity in order to contradict it or to exaggerate it. In Sections 3 and 4, transgressions to the assumedly rigid form and meaning of proper names will be explored. I will show how playing on their form can be used to distract the reader from the basic content of the message the proper name was inserted in. This gradually leads to a second level of distraction and rigidification, corresponding to the traditional meaning of "incongruity", applied to the structure of phrases: the lexical proprial unit is inserted in a syntactic context that forces the reader to reinterpret its overall meaning, giving rise to a surprising gap between the meaning of the original structure and its actual meaning in context once distorted by the use of a proper name. Finally, in Section 5, I will describe how, as proper names become lexicalized - this time in the sense of undergoing fossilization that will lead them to be integrated into the lexicon (Brinton \& Traugott [2005: 45]) -, the properties attached to their referents also go through some kind of reduction and rigidification that may give rise to humorous effects, by making proper names degree expressions used to exaggerate their referent's properties.

\section{Theories of humor. why a Bergsonian approach to incongruous proper names?}

5 I will start this review with somewhat of an obvious statement: "There is no universally accepted definition of humor" (Gulas \& Weinberger [2006] quoted in Warren \& McGraw [2016: 407]). Instead, humor has given rise to multiple theories or even "families of theories", the two most important of which are the psychological-psychoanalytical and the social theories of humor (Mulder \& Nijholt [2002], Popescu [2003]). Within these families, three major trends emerge that define humor as either an expression of 
disparagement of the addressee and/or a third party and superiority of the speaker (Superiority Theory), a means to release tensions (Relief Theory), or simply a tool used to facilitate integration and interaction within a community, to solve problems or to avoid problematic situations by playing the "it was just a joke" card and taking back what had just been said (see Attardo [1994: 323] on social management, decommitment, mediation and defunctionalization). Bergson's theory of humor belongs to that last trend of social theories of humor, since he describes laughter as the expression of a social judgement upon something perceived as abnormal that needs correcting in order to be accepted again. Because proper names are primarily used to refer to people, institutionalized places and times, as well as human productions, and because understanding a proper name requires the (co)speakers to conjure a set of encyclopedic properties attached to its referent, they are inherently part of a social dynamic: using a proper name, be it humorous or not, is a social act. Choosing to coin a humorous proper name, or to use a non-humorous proper name so that the result is considered humorous, is a social statement.

6 Which begs the following questions: what is considered humorous and how is humor achieved? A first approach would be to look for humor in the symptoms it provokes hence the wealth of studies on the functions and meanings of laughter, and the immediate connection made between humor and some form of pleasure. For instance, Apter's theory of reversals [1977] posits that humor occurs when someone is in a "paratelic" state - i.e., a state in which actions are meant to be done or interpreted without any goal in mind, as opposed to a "telic" state which is goal-oriented -, easily reduced to a non-serious state. Processing visual, verbal or social stimuli triggers arousal, which, in large quantities, leads to anxiety in a telic state and excitement in a paratelic state; humor is therefore seen as the cause of positive excitement due to the involvement of the speaker in a non-serious or non-goal-oriented environment. Except proper names often appear in contexts that seem very much telic, since they can be used as default name tags for any entity that has a name in most conversations - when there is no competition between the use of the entity's name versus a definition description. Even when a company coins a humorous (sometimes disparaging) proper name for one of its brands, such as Reckless Drivers (chauffeuring service), Ill Advisors (medical consultants) (Rutkwoski [2016]'s examples, see Section 2), they still intend to use that proper name as a commercial tool that will attract potential customers and help them make a profit; the proper name is thus both goal-oriented and humorous at the same time. This is the name that will appear on contracts and deals, and maybe in lawsuits - all of which are neither positive nor non-serious contexts, and yet the proper name may (or may not) still be felt as humorous upon reading as it was when originally coined. One interesting element of this theory, though, is arousal; arousal in itself is not positive or negative, only its effects are. It is therefore licit to compare arousal to a certain amount of challenge from the speaker (or to the co-speaker), a challenge that would be translated into a threat in non-humorous contexts, and merely into violation, some linguists would say, in humorous contexts. As Veatch [1998] puts it, "Humor is (emotional) pain (V) that doesn't hurt (N)" [V stands for Violation; $\mathrm{N}$ stands for perception of the situation as Normal].

7 In fact, the idea that humor is to be seen as a rather benign violation, "wrong yet ok, threatening yet safe" (Warren \& McGraw [2016: 407]), leads to two observations: 1) aggressiveness, or some form of violence, is part of humor (as disparaging nicknames 
and demeaning jokes show, cf. Superiority Theory) and 2) it must be on a gradient. Therefore, irony and sarcasm - when they are not equated in the literature as a means of mockery and criticism via the speaker's lack of endorsement of what they just said could be organized on a cline toward more aggressiveness in humor, with sarcasm at the aggressive end (Tabacaru \& Lemmens [2014]), until they become too aggressive and lose their humorous quality (for more on the distinction between humorous and nonhumorous irony, see Dynel [2014]). On the contrary, lack of (enough) aggressiveness with a large amount of challenge results in too much cognitive effort rather than too much violence, and the perception of the production's humorous quality decreases too. An instance of wordplay, even good, that is too intellectual and too little connected to the source expression it distorts, is not judged humorous. Giora [2002: 11-12] explains how departing too much from the normal situation does not result in more violation but rather in no recognition of the original normal situation, the consequence of which is a misfire. An optimally innovative stimulus that induces pleasure (and which is therefore equated with humor) must be a "novel response to a familiar situation" that still allows for the [quick / easy] "recoverability of the familiar" - something that is not familiar but not too innovative either. This is probably what awaits some humorously coined or used proper names when they rely on homonymy or paronymy with common nouns, adjectives or adverbs, because their reliance on linguistic knowledge suddenly makes them very / too learned: too close to another part of speech, or too often used as a frequent proper name, and the proper name alone (Mr. Smith and being a smith) cannot be humorous unless heavy context backs it; too creative and the connection to the original form gets too thin to be perceived, and no violation, hence no humor, ensues ${ }^{1}$. When the proper name is humorous because of the encyclopedic knowledge it evokes, i.e. when proper names participate less in linguistic humor and more in "cultural humor", then no such difficulty is observed. Rather, Antonopoulou [2004: 248] advocates for preserving proper names in translations of humorous texts because on average, they were judged more humorous than any replacement with a (common) noun phrase due to their brevity, high degree of specificity and their ability to provide "faster access to concrete, image-like scenes than descriptions (including common names)".

These descriptions all point towards the idea that, in humor, what is funny is the recognition of what is not (the normal situation) that yet could or should be. This tension between two situations - a theoretical, normal one, and a (surprisingly) different one - is at the heart of the main conceptualization of humor: incongruity, be it defined as surprise / unexpectedness, or a contrast between two opposing ideas, meanings or scripts (in Raskin's then Attardo \& Raskin's terms), or the difference between a situation and a typical situation (Warren \& McGraw [2016]). Several criticisms can be made that justify why the standard framework for incongruity - the now mainstream General Theory of Humor - was not found entirely adequate for this study, and why I chose Bergson's primitive - because old and not entirely formalized theory of humor as a starting point for the study of humorous proper names. First, as just presented, no agreement has been reached as to what incongruity precisely means. Second, because there is doubt as to whether it is incongruity, or its resolution that leads to humor: incongruity resolution is widely acknowledged as the cause of humor (Mulder \& Nijholt [2002]) but it does not explain why sometimes humor is found, especially with children, when incongruity is present without the means to understand or explain it (Forabosco [2008]). Third, because it is not certain incongruity theory is 
still completely sufficient to explain humor, as it focuses more on violation and contrasting scripts being forced upon the co-speaker and not enough on cooperation and the possibility of humor without contrast between simultaneous scripts; or even if incongruity is the cause or a possible by-product of humor (Forabosco [2008], Veale [2004]). For example, when one speaker in my corpus nicknames his step-father Cam, a cowboy, Cowboy Cam, there is no contrast or simultaneous hold of two scripts such as "cowboy (behavior) - not cowboy (job-description)": what is humorous is the fact that Cam indeed is a cowboy and (will forever remain) only that. Finally, because this general theory of incongruous humor is an extension of a semantic theory of humor (Raskin's SSTH: script-based semantic theory of humor) which, however essential, is not the only tenet of humor - especially for proper names, where incongruity can be found in other places such as morphosyntactic, conceptual and referential levels.

Section 2 deals with some aspects of semantic incongruity involving proper names, rejoining Rutkowksi [2016]'s findings, but the main goal of this article is to show that proper names have the potential to be humorous even before semantic scripts are involved, and that their morphosyntactic status may give rise to humorous meanings that play with the metalinguistic properties and semantic consequences of their nominal status. I will therefore suggest a few metalinguistics script oppositions to describe how proper names as lexical units can be used humorously. In a way, I want to show how proper names showcase the linguistic system they belong to and how they use its driving forces in order to better indicate when they behave unexpectedly. Such a description is very consistent with a mechanical view of humor, as Bergson's theory has been tentatively described (Attardo [2014: 78]).

Bergson has given a description of humor that has been regarded by many as one of the precursors for the Incongruity Theory. His understanding of humor rests upon a few ingredients, first and foremost, rigidification, made explicit to us via distraction or absentmindedness, and emphasized through exaggeration.

The laughable element in both cases consists of a certain MECHANICAL INELASTICITY, just where one would expect to find the wide-awake adaptability and the living pliableness of a human being. (6A)

In the first place, this view of the mechanical and the living dovetailed into each other makes us incline towards the vaguer image of SOME RIGIDITY OR OTHER applied to the mobility of life, in an awkward attempt to follow its lines and counterfeit its suppleness. (14A)

The rigid mechanism which we occasionally detect, as a foreign body, in the living continuity of human affairs is of peculiar interest to us as being a kind of ABSENTMINDEDNESS on the part of life. (28B)

This corrective is laughter, a social gesture that singles out and represses a special kind of absentmindedness in men and in events. (28B)

This is the real explanation of light comedy, [...] - an artificial exaggeration of a natural rigidity in things. (33A) (Bergson [1911], my emphasis)

Applied to language in general, rigidity corresponds to "ready-made formulas and stereotyped phrases" as well as automatized patterns of speech, or when "an absurd idea is fitted into a well-established phrase-form" (Bergson [1991: 35B-36A]). Applied to proper names in particular, the established form is sub-phrasal and corresponds to the "nominal" slot within a noun phrase, along with typographic cues such as capitalization. Absentmindedness and distraction operate at two different levels: being akin to constructed nouns, proper names may use lexical creativity as a means to arrest the readers' attention and force them to register the name of an entity that is 
otherwise automatically used without even thinking about it; being semantically opaque and largely considered "meaningless" or lacking the same predicative meaning as common nouns, proper names may take on more semantic weight than they usually do, to the point that they are confused with appellatives, and this (incongruous) mismatch between how proper names usually behave and how they behave in the context of a humorous production reminds the co-speaker of the (rigid) semantic constraints that supposedly render proper names less flexible than other nominals. Incongruity is therefore understood as only one part of the Bergsonian distraction, albeit an important one. Finally, this perceived rigidity in the form and behavior of proper names that culminates in the lexicalization of the unit is also how proper names are able to magnify the possession of a certain property, thereby creating humorous exaggeration.

\section{Proper names, being rigid lexical units, are perfect candidates for future humorous coinage and use}

12 I have tried to show elsewhere (Philippe [2020], [2021]) that all proper names, including proper nouns, are best described as nominals. A nominal is the intermediary level between a noun and a noun phrase: with common nouns, a nominal corresponds to the head noun and its internal pre- and post- modifiers:

Table 1. Different nominal levels: nouns, nominals and noun phrases

\begin{tabular}{|l|l|l|l|l|}
\hline noun & car & & & \\
\hline nominal & red car & United Kingdom & Monet & Play to the Whistle \\
\hline noun phrase & A red car & The United Kingdom & $\varnothing$ Monet & $\varnothing$ Play to the Whistle \\
\hline
\end{tabular}

13 These proper nominals tend to blend in with other nominals, which they do by adopting the same syntactic properties as some nouns and by being very likely to be reduced to a single unit: Talk-Talk >> TalkTalk, United Kingdom >> UK. The most successful of them are the mono-lexical units called "proper nouns", which look the "noun" part the most - hence Monet usually being described as a proper noun, being a single lexical unit, yet remaining a nominal.

Proper nominals are akin to constructed nouns, as they may combine several units (United + Kingdom, Play + to + the + Whistle) which could theoretically be analyzed both syntactically (common nominal, clause) and semantically (a kingdom whose parts are/ have been united, a process involving participants and a whistle being blown), and yet which must be analyzed as a whole. Play to the Whistle may have the form of a clause, as a proper name it does not refer to a process but to a game (a "nominal" entity) and it syntactically behaves like a noun, entering close appositions as in this example:

(1) The shows he is set to ditch include sports quiz Play to the whistle and daytime quiz Cash Trapped. (Mirror online) verbal or adjectival predicates, now refer to entities most aptly signified by nouns. I 
therefore argue that the creation of a proper name out of any sort of linguistic unit has a reification effect (turning anything into a "thing"': object, person, place, time... all nominal referents). The concept of "reifying units" is highly relevant for this study, as it is a first step towards lexical rigidity (which can then be amplified and/or distorted for humorous purposes).

16 This rigid behavior is illustrated by the impossibility to replace one element of the proper name by another: Cash Trapped is not Money Trapped, Play to the Whistle is not Play with a Whistle or Dance to the Whistle. This impossibility is not even due to some kind of compositional meaning of proper nouns: even if some proper names can be analyzed semantically, there is no guarantee that the whole proper name refers to the kind of referent that its combined parts describe when they are not in a proper name. Take, for instance, GrandMother's Footsteps, a game in which one person faces a wall, counts to three while other players try to sneak up on them, turns around to eliminate any player who has not stopped moving on three. There is no actual grandmother involved, and the player representing the figurative grandmother is the one counting, not the one approaching step by step. Likewise, Lemonade is the proper name of an album by Beyonce, not a soft drink. In the end, English speakers must assume that there might be no connection between what the proper name reads and what it actually means or refers to: a proper name does not necessarily say what the referent is - and the referent may not be what the proper name says it is -, it just says that it is, and that it has a name. This opacification of meaning, which corresponds to a rigid semantic constraint on proper names, can be turned around when using a proper name with humorous intent.

Rigidity also affects their referential behavior - or so the average speaker assumes, and philosophers of language contend (Strazny [2011]). After all, proper names are mostly famous for being "rigid designators" (in Kripke [1980]'s terms,), that is, to be uniquely referring expressions that denote - but do not connote (Mill [1843]), i.e. do not describe or use a stabilized set of properties to refer to an individual - the same individual in all possible contexts (strong version) or at least in one specific context when no ambiguity is possible (weak version). On the contrary, common nouns are used to stand for categories of objects drawn from a set of stable properties that will become their socalled "descriptive meaning", and they will apply to any entity possessing these properties. Two individuals sharing the same name (Bill $l_{1}$ and Bill ${ }_{2}$ ), or a proper name identical to the noun for a category of objects (Bill and bill), are seen as accidental instances of homonymy. But because proper names are referentially rigid, the intended referent is claimed to be easily recoverable and no threat to reference is posited. This semantic rigidity has a syntactic counterpart, as most descriptions of proper names usually amount to a list of syntactic constraints that make "true" proper names different from common nouns: no plural suffix and no visible determiner (barring exceptions like the Himalayas), lack of contrastive definiteness (Bill vs. a Bill), lack of (non-restrictive) modification (*Bill who is my colleague).

When linguistic research offered proof that these rigid patterns were not always respected (I know two Bills, I met a Bill today; Other people settled for Office Susie, so as not to confuse her with Heroin Susie), the immediate response was to reject these examples from the category of proper names and make them cases of recategorization into common nouns. This choice at least meant no breach in the inherent rigidity of proper names. Further research led to the recognition of the existence of 'modified proper names', i.e. 
units still regarded as proper names that can, in certain syntactic and semantic contexts, take on properties previously restricted to common nouns. As a consequence, syntactically less rigid proper names also become semantically less rigid. If I know two Bills, then maybe there is a category of objects sharing the property "being called / Bill/", which makes proper names less rigid designators and more common noun-like, acquiring some kind of meaning. My own syntactic and semantic description of proper names accounts for proper names gradually taking on properties of common nouns as they become more integrated into the noun phrase, while still retaining their status as proper names. Note however, that nothing here is perceived as funny in I know two Bills. But such a possible departure from their rigid behavior, which is perceived by many as their only or at least main linguistic behavior, could be used humorously when interacting with other linguistic units in context: compare I know two Bills (no humorous intent) and I have many b/Bills to pay (if several of your employees or creditors are called Bill, for instance; humorous potential and perhaps humorous intent).

This is what Rutkowski [2016:132-133] focuses on: she identifies that semantic incongruity in proper names arises from the perception of the opposition "meaningless - meaningful" juxtaposed to another opposition "name - not name" (understand: proper name - appellative / common noun, adjective, etc.). As stated before, these perceived oppositions might not be enough, and she adds context into the mix: the context will contain elements called catalysts that will influence the reader toward a humorous reading. She also identifies proper names with "greater humorous saturation (and therefore, a greater probability of humorous interpretation", which illustrate another opposition "neutral - not neutral": those proper names contain a lexical unit denoting topics unfit for polite society (violation of social norms of acceptable topics of conversation) such as colloquial or vulgar words, or words denoting physiological, scatological or sexual attributes - Glasscock, Hickinbottom, Assloss, Colon, etc. (her examples). What is humorous then is, however, not the fact that these names convey meaning, but also connotations (added, non-distinctive semantic values (Kerbrat-Orecchioni [1977: 18]) that have, again, a lot to do with context of use. In that respect, disparaging names for companies, people and places are even more humorous because they potentially violate the face-preservation principle implied in conversational guidelines, by breaking linguistic politeness under the cover of the excuse that "it's just a name". A greater degree of humor could therefore be achieved when this is done purposefully, when the speaker creates a nickname (see Section 5). Two observations can be made:

1) The opposing semantic scripts identified as relevant for humorous proper names do not involve a contrast between extralinguistic properties attributed to a referent ("big - small", "nice - mean", etc.) but between metalinguistic properties attached to the definition of a linguistic unit: lexical category, semantic content, face-threatening act.

2) This interpretation of humorous proper names only allows meaning to be taken into account when it is that of the homonym appellative, but what about some meaningful information about the referent attached to the use or coinage of a proper name? Not having the same "descriptive" meaning as common nouns does not mean having no meaning at all, and proper names could use that to elicit humor. This particular meaning, which I call associative meaning, derives properties from the encyclopedic knowledge of the referent. 

proper name make it impossible to restrict a proper name's referent to the sum of the potential referents of its parts (non-compositional structure), so that the reader has to assume that a proper name's referent has many more properties than the (few) ones implied by its name, should it be motivated by some sort of resemblance with its referent: the United Kingdom is so much more than a kingdom united some time ago. Proper names being expressions used to refer to qualitatively unique entities, humor may thus arise from the reduction to some traits of the proper name's referent, instead of referring to their whole identity, therefore reducing them to sharing the same traits as other (common) referents, or reducing them to archetypes (expression of degree as a humorous device). Humor then comes not from two opposing scripts, but from leaning too much into a single, (over-)simplified script, when proper names are built for conveying complex and multiple extralinguistic properties at the same time.

One last linguistic property of proper names needs mentioning. As proper names semantically reify and syntactically nominalize, they can welcome various units that are hard to classify elsewhere due to their unusual (non-lexical) form such as email addresses, combinations of numbers and/or letters and even symbols such as hashtagged content:

(2) There was a message at the top from aboyd@cinnamon.com. (Hawkins [2016: 50])

(3) When she moved onto Thirteenth Street, Arleen was receiving W-2 T, owing mainly to her chronic depression. (Desmond [2016: 53])

(4) I type "password"; I type "1234". [...] I cracked the laptop password eventually: it's Blenheim. (Hawkins [2016: 314])

(5) Notably, none of these designers referenced anything on social media this is very much about an IRL, no filter rather than \#nofilter view. (The Guardian, Culture [10/01/2017])

Now this property does not seem to fit with the overall rigid structure of proper names, since one might expect selection of the lexical units that can become proper names. In fact, almost (if not exactly) anything can be turned into a proper name: nominal, adjectival, verbal, clausal units, grammatical items (You, the name of a TV series), so why not non-lexical forms? What these illustrate is that rigidity does not affect admission into proper name-status, but it affects the resulting proper name. As a consequence, these odd-looking proper names magnify this rigidification process by being distractions par excellence. These units stop the readers in their tracks as they do not conform to the normal aspect of lexical or grammatical units - and that is the first step to identifying potentially humorous use of proper names.

\section{Humor as an arresting device: inherent typographic and morphosyntactic parameters of proper names that can be used as a first step toward humor}

Bergson starts his description of humor with the idea that it arrests the attention of the audience, forcing it to notice something that it would otherwise discard. Humor lies in the realization that something is not as fluid as it should, that something has been rendered mechanical, or unnatural. In other words, the first step to humor is to 
acknowledge that something is amiss or out-of-place, so that the reader needs to pause and ponder on what is askew (the "hang-on" step, so to speak).

of course, not all typographic devices that force the reader to take a moment to process them are used humorously. What follows is a presentation of devices that gradually take on humorous potential, starting with when they are used non-humorously. Such is the case of the initial capital letter. Capitalizing proper names is a linguistic convention in English, which does not capitalize other lexical units (the way German does all its nouns for instance). This in turn suggests that there is a reason, in English at least, for using a capital letter to indicate proper name-status in addition to marking the beginning of a sentence. Capital letters are said to have typographic salience (as a visual mark standing out from the lower case that is regularly used), linguistic salience (marking the beginning of a syntactically constrained unit following distinct rules) but also moral, emotional or social salience (glorifying the referent's higher status or qualities by using an iconically higher case, Gary-Prieur [1991], Edwards [1996], Graphèmes [2010]). By being capitalized more often than not, proper names stand out compared to the rest of the sentence: this alone does not make them humorous, but ensures the reader sees them and takes the time to process them (and process whatever humorous intent they may display). Besides, capitals at the beginning or within a proper name force the reader to acknowledge a distinct linguistic unit that was constructed, as capitals should not occur mid-unit (NyQuil), and to wonder why there was a need to have such a constructed unit in the first place - looking out for potentially missing information, going beyond what is superficially said.

(6) Elder Johnson, Bishop Dixon, Sister Atalya-none of them knew Crystal was staying at the Lodge. Only Minister Barber knew. Crystal didn't want members of her church to reduce her, to see her as an object of pity, a member of "the poor and the orphaned." She wanted to be seen as Sister Crystal, part of the Body, the Beloved. (Desmond [2016: 210])

In example 6 for instance, humorous potential arises from the systematic use of capitals that mark a very solemn (religious, spiritual) context due to the mentions of the Body (of Christ) and Christian love (Beloved). In addition to that, the previous reference to members of the Church by their (capitalised, since institutionalised) titles of Elder, Bishop and Sister, makes the reader interpret Sister (Crystal) as the title of a female servant of God - and not just a fellow Christian. This reading, suggested by the use of the capital letter, is humorous considering the troubled young woman has a history of inflicting verbal and physical pain on others, as well as prostitution, properties that do not exactly match the representation of a nun.

In the following examples, the capital letter participates in a humorous intent as it gives set phrases proper name-status (or proper name-like status for example 8) when they should not be analyzed as such:

(7) Perhaps he was afraid I was going to Do Something Stupid. (Hawkins [2016: 362])

(8) he had, as usual, reserved the entire front row, so as not to find himself sitting next to that famous bore, God-Knows-Who (St Aubyn [2015: 240])

Example 7 shows how the use of capital letters turns the process signified by the expression into a concept and thereby tends to lend it even more importance than the speaker seems ready to give it, which renders the idea of "doing something stupid" 
ridiculous itself. Example 8 takes it one step further and reifies the concept by creating a generic person whose name would be the anti-name God-Knows-Who, giving an identity to the anonymous.

(9) A short lecture, delivered at the point of arrival, entitled Are You Really Sure You Want to Live Here: Most People Are Awful and Blame You For Not Having Blue Passports Any More, Plus Katie Hopkins Lives Here. (The Guardian, Opinion [10/01/2017])

This last example may already be seen as humorous even without processing what the proper name means. The capital letter is supposed to mark the beginning of a unit yet here, capitals are everywhere: granted, proper names allow for capitalization of all units to indicate both where they start and where they end, but this proliferation of capitalized words sheds doubts on whether this proper name does end at some point, and whether is it still a suitable proper name. This leads to a second level in humorous use for it: the reader realizes that probably most if not all of the (short) lecture is contained in its title, which defies the point of a title in the first place - and defies the point of a proper name, which is primarily to denote without connoting (too much). Only then can the content of the title be analyzed for humor at a third, semantic level. Typography is thus considered here the first-level entry to a layered understanding of humorous proper names, which relies on linguistic proficiency (when to use a capital letter, how to use a proper name and what for). Backronyms - re-creating meaning from a word-form made of capitalized letters that do not necessarily have an expanded form - and diverted acronyms like DMSO - Defense Modeling and Simulation Office becoming Defense Meat-eating and Salivation Office (Stock \& Strapparava [2002]) are further evidence of that.

Playing with linguistic patterns is at the heart of the humorous effect associated with coined proper names, that is, proper names that are not drawn from an alreadyexisting list, but are created for fictional or advertising purposes. These include brand names or book/song/artistic work titles and names of commercial or political organizations - which fall into the Attention-Seeking Devices (ASD) and are closely linked to humor (Munat [2007]). When reduced via clipping - Shop-Vac -, initialism G\&T for Gin and Tonic - or the "often cute or amusing" blends (Lehrer [2007]) - NyQuil/ DayQuil, Middletucky, Brexit, Medicare, Febreze, Ziploc-, when pseudo-affixed - Kleenex, Windex - or condensed into one lexical unit instead of several - Filet-O-Fish, Want2Stay, WeChat -, when resting on orthographical/phonological alteration and games - Beatles, Everbrite, Ziploc, Handy Andies, Sweaty Betty, Meals on Wheels - proper names force the readers to slow down and work their way through decoding the combination and finding the right referent behind the name. Want2Stay, for instance, challenges the readers to first identify three different sub-units (Want, 2, Stay) - which they are able to do thanks to capitalization and use of symbols as automatic delimitators - then realize the homophonous substitution of the infinitive particle to with the number 2 in order to make sense of the resulting clause (Want to Stay) while still considering it just a proper name. This (linguistic) effort ${ }^{2}$ has been correlated with some kind of satisfaction at having found the solution to the pun (Balteiro \& Bauer [2019]) - which the co-text can help with (the picture of the old seaman on the crunchy cereals' box helping not to read Cap'n Crunch like, say, Pick'n'Save). Examples of humorous lexical creations are not restricted to proper names, however, and belong to the category of wordplay, defined as both creative and playful (because involving at least two inputs) word-formation by 
Renner [2015]. His account of wordplay may be interpreted as another metalinguistic opposition script, since wordplay is seen as torn between "two antagonistic (albeit coexisting) functions of word-formation: its naming function, and the corollary information condensation function in the specific case of complex words, and its ludic (i.e. playful) function" (Renner [2015: 129-130]). Foregrounding of the naming property leads to non-humorous constructed terms used in technical fields ("bit", "splake"), foregrounding of the ludic property leads to playfulness and therefore wordplay.

Some proper names score very high in that respect, like numerical proper names in the form of hashtagged content - where the hashtag replaces or complements the initial capital letter as a linguistic boundary and typographic distraction. Caleffi [2015: 66] notes that hashtagged messages express a very strong emotional involvement from the speaker, which makes the \# symbol equivalent to a pre-posed exclamation mark, whose main purpose is to make sure the reader focuses on the rest of the hashtag's content and its cotext. Gradually used in advertising, \#hashtags also found their way into politics and are often used as markers of sarcasm (\#spasiboputinuzaeto, 'thankstoputinforthat', (Lunde [2016]), \#FeministsAreUgly (Lawrence \& Ringrose [2018]), \#DonaldTrumpTheMovie and 'hashtaggery' (Chiaro [2017]) in addition to being associated with a form of exaggeration (see Kunneman et al. [2015]). Hashtagged messages may be used humorously because of the combination of their form (condensed, typographically and emotionally salient) and the context in which they are used: \#sarcasm or \#AmericanDisaster (Zappavigna [2018]) after a quote or a tweet will give the key to interpreting the text, sometimes contradicting the expected interpretation. Humor then relies on two separate components:

1) the micro-packaging of information, which amplifies its messages by reducing it to one single property (\#sarcasm is full-blown sarcasm, see Section 5 on exaggeration and the expression of degree), so that the reader is figuratively struck by the gap between the (reduced) informational tone of a short text on social media and the evaluative comment that follows,

2) the context of usage, social media, which enables the hashtagged unit to be used as an iterative marker that can be repeated over and over for different messages by various users - repetition being another humorous device described by Bergson, as it forces the reader to observe the faulty mechanics of a situation, which is stuck on repeat and unable to move on.

Hashtagged units also allow more easily for some sort of productivity that results in humor due to the context of production. De Cock \& Pizarro Pedraza [2016] analyze how the \#jesuis (\#Iam) hashtag, originally not humorous at all as it meant sympathy for people going through terrible hardships (gradually moving on from the string of attacks in 2015 in France to anyone suffering, \#jesuisMila), was turned into a comical device used to express sympathy for referents that did not automatically stir the public's sympathy, or even its interest (\#jesuisfourmi, \#jesuiscafard, "\#Iamant", "\#Iamcockroach"). I would suggest that part of the humorous intent derives from the mismatch between what is expected of a proper name in general (even a numerical proper name), that is, to highlight and maybe glorify its referent, heightened by the contextual significance of one particular proper name or proper name-base (\#jesuis_), and the effective hashtagged message when applied to something that the reader realizes should not "deserve" such treatment. In that case, humor is the result not of the creation of the new proper name, the form of which is not incongruous, but the use 
of that proper name in an incongruous context that activates all the properties attached to a proper name, except for one (high value of its referent). This example also hints at the potential for humor that comes from productivity with proper names, or how changing one component in a supposedly-rigid lexical unit gives way to a whole new meaning that contradicts the reader's expectations of the message and the inner working of proper names.

\section{Rigid, un-analyzable units and lexical alterations: canceling the proper name or accommodating it?} highlights a certain form of rigidity that should not be there, jamming an overused system; but proper names being rigid lexical units that cannot be altered, it is precisely trying not to use them rigidly that makes the reader notice that something is out of place, or character.

the typographic devices presented in section 3 are striking enough, a nonhumorous proper name is almost forgotten right after the reader has read it. A proper name being the default means to refer to an entity if it is known, it should not stand out in order to ease communication - hence the set of conventions such as rigid designation, no possible lexical alteration or semantic weight that the reader can rely on to make it a necessarily odd yet familiar unit in the textscape. If any of these parameters change, then the reader's attention will not be primarily on the rest of the message; instead, it will be diverted to the proper name in order to understand why it does not behave as it should. Compare two situations: a fashion show with models wearing a t-shirt reading Boss International (a well-known fashion name), and one wearing a Loss International $t$-shirt. While the first proper name is expected in context and will barely be noticed, the second, having been created as a clear by-product of the first one, will draw attention onto itself, and make the audience question its very existence. By making proper names less rigid, humorous uses force the reader to recognize that there should be something rigid in the system in order for the rest of the sentence to take precedence. This is a highly metalinguistic feature of proper name humor, as it comes from the reader's direct recognition that a linguistic rule has been broken. In the remainder of this section, I analyze various forms that this misshaping of proper names can take as well as the kind of consequence it has on how the proper name and its referent are conceived by the reader.

Hashtags are not the only proper names that can be productive, or re-produced. If some proper names have to be thought in terms of a series - World War I/II or First/ Second World War; London 2012, Rio 2016 - so that mirrored patterns are not humorous but expected, other proper names re-using previous proper name material are doomed to become problematic and therefore humorous.

(10) Didier, on the other hand, he dreaded seeing [...] because he was always trying to get Alan to publish his books in England. His latest assault had been at a drinks party at Katherine's when he'd been trying to peddle his new book, Qu'est-ce que la Banalité?. [...] "I'm sorry," Alan said sensibly, "but we can't publish a book in England called, What is Banality?." "Call it The Anatomy of Banality," suggested Didier, following Alan into the kitchen. "This will appeal to Anglo-Saxon materialism, and also the echo with The 
Anatomy of Melancholy signals that it's a serious work, no?" "Of all the things that don't need analysing," Alan began, but Didier interrupted him straight away. (St Aubyn [2015: 55])

A French philosopher is confronted to several difficulties when trying to sell his book to an English publisher. Regardless of the contents of the book, he doesn't see how his choices of book titles (proper names) are unfortunate, for several reasons that pertain to the fabric of a proper name. First, unless they're fictional and motivated (Professor Sprout in J. K. Rowling's Harry Potter >> Pr. Chourave in the French translation by JeanFrançois Ménard) or they come from the same root as other commonly used names (John, Jean, Yoann, Johannes) proper names are not supposed to be translatable: it is one of their traditionally defining properties, along with lack of determination, modification and meaning. When proper names are translated, they're very seldom done so word for word: by trying to get the English title to resemble the French one, the author in example 10 completely misses the point of a proper name, which is to be a highly context-dependent and language-dependent unit that cannot cross languages without getting noticed. At this stage, the proper name What is Banality? would be equivalent to a foreign unit that does not exactly fit the English pattern, and a unit that is not entirely suitable as a name/title. Then, in an attempt to conform to the saidEnglish pattern, the author tries another proper name that is directly inspired from an already-existing one. The process is roughly the same as with the \#jesuis hashtags and the result is jarring too. In addition to ridiculing the second referent (lending as much philosophical interest to banality as to melancholy, something the English publisher doubts should be done), it also backfires on the referent of the original proper name. For descriptive proper names at least, which are coined for a specific referent whose uniqueness is iconically mirrored by its unique denomination, repetition of the same lexical pattern for another referent which has no ties to the original one can only deprive it of part of its originality. Indeed, by creating The Anatomy of Banality out of The Anatomy of Melancholy, without justifiable connection between the two works, the French author is creating a lexical base, or placeholder, The Anatomy of _ that would, in his mind, apply to any "serious work", regardless of its impact, relevance, genre, and so on. In fact, what is humorous is this casual reference to a marketing strategy as it makes the reader realize the existence of this rigid placeholding, mechanical function of some titles in real life, since it is indeed being used outside fiction. Google Books shows countless works entitled The Anatomy of Racial Attitudes/Grief/Peace/Fake News/ Consumerism/Desire/Sport Injuries/Yes, etc., rendering The Anatomy of_ a generic form for any book title, regardless of the book's unique features. The French philosopher's argument is therefore that his book's originality is best exemplified by the use of an oversold formula that does anything but make its referent unique. This rigidified book naming strategy can be translated into the following opposing meta-scripts: "original not original", "uniquely referring expression - generic placeholder" that derive from the more general "fit - unfit (proper name)" script.

For the same referent, what might seem like a minor alteration to its name may also result in ridicule. By minor alteration, I do not mean the addition of suffixes that would lead to the recategorization of the unit into a (verbal) predicate. Take the example of a novel competition called the Elysian Prize: as rounds of selection go by, some authors will appear on the Long List (first round) then on the Short List (second round) before the winner is announced. The selected candidates are called Long-listed then Short-listed authors, and they may be congratulated on their Short-Listing. This is not humorous but 
derivational use of proper names. Instead, humor-inducing alterations are those which occur within the proper name itself, corresponding to a paradigmatic change of one or several of its morphological / phonological components.

Consider these alterations to the proper names, by two different characters, one of whom is not a native speaker:

(11) He could imagine that the press would want to make a bigger splash by synchronizing all the profiles [...] with the explosive appearance of Mulberry on the Elysian Big List. [Sonny, an Indian grandee full of delusions concerning his novel and his own importance]

(12) "I am the speech writer for one of the Small-Listed authors," said Didier, hardly able to contain his mirth. [the French philosopher] (St Aubyn [2015: 42-43, 225])

By replacing Long by Big and Short by Small, one could argue that no significant change has been forced onto the original referent. After all, if the list is a Long List, it's probably big, and if the list is a Short list, then there is a smaller number of authors on it; the alteration is minor due to the near-synonymy or semantic closeness between the adjectives long/big and short/small. Part of the humorous effect comes from the "trace of meaning" (in Raynaud's words [1977: 27-28]) that justified the replacement of a word by another: long and big or short and small may be synonyms in some contexts, but not in others, mis-using one for another can lead to an amusing gap in meaning. However, with proper names it goes beyond the simple momentary inadequacy; whereas someone may be able to re-construct to be short-sighted from to be small-sighted, or to be a big girl from to be a long/huge girl, I would argue that replacing part of a proper name by a close synonym does not just deform the proper name, it sometimes cancels it. It is so because, contrary to phrasal lexical items (Kuiper [2007]) which may be altered for humorous purposes and still be recognizable, more lexicalized units such as proper nominals rely on their fixed frame to keep their naming function. Saying that there is a Small/Big List is not naming the list by its name, it is saying that the list is very small/ big indeed. With near-synonymy, so-called descriptive proper names - whose descriptive parts should not be automatically understood as characterizing the referent even if they very often do (see Section 1.) - truly become descriptive expressions and therefore less of proper names. Rather, Big List and Small List would be closer to nicknames, emphasizing one aspect of the List without properly naming it - hence the idea that the Small List is somehow smaller than the Short List (Section 5). In addition to turning the reader's attention to the meta-linguistic rigid structure of proper names, this acts as a meta-judgement on the linguistic proficiency of the speaker who made that mistake, which in turn participates in a broader humorous mockery of the character as a whole: Sonny has submitted a novel everyone thinks is a pompous drag that shows he does not understand how to properly write a novel, so it is only fit he should not know how to properly name the writing contest he has entered. As seen in example 10, Didier is more interested in being part of the literary scene than he is in understanding the subtleties of that scene, so replacing Short List by Small List is very consistent with previous linguistic violations.

Perhaps the proper name's original purpose does not always disappear altogether, so it would be too strong to speak of canceling the proper name, when it only distorts it or even accommodates it. This is particularly relevant when a distorted proper name is intended for another referent than the original proper name's, and when permutation 
is replaced with addition of linguistic material. Consider A Brave New Arctic, the title of a documentary showcasing how scientists from all around the world work hand in hand to save the Arctic (positive connotation), derived from the title of the dystopian novel $A$ Brave New World, depicting a frightening society governed by new technological advances. Reference to the source proper name is not cancelled but distorted enough to mean the opposite (glorification vs. fear of technology, approval or disapproval of humankind), with a possible suggestion that the ultimate source of inspiration for the name, whose positive connotations had already been distorted in Huxley's novel, are rehabilitated in the documentary's title (Shakespeare's The Tempest 1.5.183-184: How beauteous mankind is! O brave new world, / That has such people in't').

Proper names may either be the targets of the alteration or its instruments. For instance, a proper name inserted in a larger syntactic unit it does not normally belong to will - of course - influence its interpretation but not necessarily cancel its original meaning. In Show me the Monet, the title of an article detailing the heist that took place in a museum (Mariaule [2008: 63]), the proper name Monet is a transparent replacement for money in the original expression (show me the money). However, it is only due to their close homonymy (Monet and money being quasi-homographs and, to a lesser extent, quasi-homophones - "traces of forms") that the reader is able to retain some sort of connection with a robbery. Indeed, replacing money by any other proper name (show me the Rembrandt / show me the Long List) might not have been enough for the reader to keep the original expression in mind, as other expressions might have been available (such as "Show me the meaning", a song title). What happens then is that even as the proper name Monet stops the immediate interpretation of the expression, its formal proximity to the word it replaces also forces the reader to accommodate the expression's new meaning with some property associated with the proper name: if show me the money is still recognizable, then some of its meaning must be kept ("robbery"), if Monet was added, then something in connection with its referent fits into the semantic frame of a robbery (Monet refers to a painter and by extension, to his paintings, which are deemed valuable, thus worth being robbed): hence the delayed interpretation of an art robbery.

Most of this pun is due to the paronymy between Monet and money, a linguistic tool frequently observed in press titles. Analyzing titles such as Tout fou Lacan ("everything is going to the dogs" + fou "crazy" + Lacan "psychoanalyst fond of puns"), Lettres et le néant (from Sartre's L'Être et le Néant - "being" vs. "letters") or even We have a dream, Sullet-Nylander [2018:247; 251] describes their main strategy as a linguistic and cultural défigement, or de-rigidification, a process whereby a set phrase or fixed expression / unit is being remotivated without changing the overall meaning of the source expression (linguistic de-rigidification) and relying on cultural landmarks (cultural de-rigidification). Even though proper names should be banned from such derigidification processes, she notices that no such thing happens, as proper names have a prominent position in these de-rigidified patterns in her corpus. This de-rigidification is mostly achieved through paronymy, which is the main ingredient of Rabatel [2011a], [2001b]'s explanation of humorous proper names as illustration of an à peu près ("approximation" figure). Monet and money, Loss and Boss (International) are panonymic in that there is at least one orthographic or phonological permutation leading to the approximation of the proper name's referent with that of the resulting altered lexical unit. Rabatel explains that these alterations allow for the cumulative perception of the 
denomination value of proper names as well as the representation of the properties of the paronymic signifier (something is/has been "lost" with brands like Boss International), which he uses to highlight the linguistic relevance of opposing points of view even when referring to individuals by their name, and their subsequent potential to stand for a generic category of referents (back to the "categorizing - not categorizing", "name - not a name / a common noun" meta-scripts). Genericity has already been mentioned twice as a tool or a by-product of humorous proper names, but it implies that properties of the proper name's referent are somehow targeted to be the source of humor. This remains to be investigated.

\section{Typicality, exaggeration and lexicalization: proper names and degree as humorous devices}

The last humorous strategies Bergson identifies are exaggeration and repetition, because they both magnify a rigid property either qualitatively or quantitatively. I have already mentioned that some humorous uses of proper names seemed to express a high or higher quality of their referent (Cowboy Cam, erroneous Small List vs. Short List). There is in fact evidence that proper names have the potential to signify some kind of degree and that this property may be used for humorous purposes, especially famous proper names.

(13) It would, however, be a crime of Al Capone proportions not to have a Chicago-style deep pan pizza on your visit. (Mirror online [06/02/2017])

(14) After all, it wasn't every day that one found oneself enjoying Versailles levels of unabashed French luxury, with the welcome addition of modern plumbing. (St Aubyn [2016: 205])

In both examples, Al Capone and Versailles could be replaced by huge or great, even extreme (as such, they would be called boosters in Paradis [2000]'s typology of degree modifiers); these adjectives, however, would probably fall short of describing how great the crime is, or how luxurious the speaker's situation is. It therefore seems that the proper name means the highest possible degree of "greatness" in these particular examples. Fauconnier [1975:353] would analyze these proper names as "pragmatic superlatives" able to denote the highest point on a property scale: average proportions great proportions - Al Capone proportions.

One may wonder why or how these proper names are able to signify "much of" and even "the biggest amount of". Al Capone is primarily used to refer to a person, Versailles to a place, so neither of them seem to be good candidates to modify a noun expressing a certain quantity. In fact, research on proper name modifiers (Breban [2018]) shows how (non-modified) proper names could be used to refer to more than just their referent: $\mathrm{Al}$ Capone and Versailles would be instances of a typifying use of proper name modifiers, and would mean "that is reminiscent of / typical of / possessing some properties associated with" that proper name's referent. This means that the degreeinterpretation is derived from the encyclopedic knowledge of their referents, that something in the referents of Al Capone and Versailles suggests greatness or grandeur. Admittedly, not all parts of Versailles are blessed with "unabashed French luxury" and Al Capone was a man of average height. In order for the reader to understand this particular degree-modification, they have to know which properties of their referents are relevant in context; mentions of crime and Chicago should trigger the memory that 
Al Capone was the most famous gangster in Chicago, so that he is a reference when it comes to crime and Chicago; Versailles, French and luxury will most likely make the reader think of former times when Versailles was home to kings like Louis XIV who gave Versailles their reputation as a place of wealth. Humorous interpretation arises from two distinct facts, repetition of the quality and the connected exaggeration of the quality for a referent which probably did not require such saturation of that quality. The "typical of" and "great amount of" readings of Versailles and Al Capone are triggered by their insertion in contexts which already mention the properties for which they were quoted. It should not come as a surprise, then, that Bolinger's account of proper names as intensifiers appears in a section on "Redundancy and its formalization" (Bolinger [1972: 156]). Proper names, or epithets, express an evaluative comment that repeats the main part of the message so that intensification is achieved (She is such a Florence Nightingale that the ill and inform flock to her). Humor here, seems to come from the excessive saturation of one script, through repetition but also through the use of a proper name whose referent is probably too great for the description that is effectively intended. Not eating a Chicago hot dog when visiting Chicago does not get you fined, imprisoned or killed: the opposing scripts "crime - not a crime" is triggered by the reference to a crime being committed; what Al Capone does is it outbids crime in the expression of the "crime" script, which furthers the humorous intention, rather than creating it. If an opposition script were to be drawn from the use of the proper name, it would again be a metalinguistic one - one that has to do with the pragmatic relevance of invoking this proper name's referent to compare its properties with the intended referent (not eating a Chicago hotdog, staying at the Paris Ritz), when the status of proper names as pragmatic superlatives makes it impossible to ever reach their level.

Another source of humor involving this degree-reading is when one observes a mismatch between the theoretical pragmatically superlative function of proper names and the realization that they are not pragmatic superlatives in context ("pragmatic superlative - not pragmatic superlative" opposition script). Analyzing degree-proper name modifiers, Vartiainen [2019] finds that some of them may be used humorously precisely because they contradict the readers' expectation of a typical example of greatness. She gives the following example from The Simpsons:

(15) That Milhouse is going to be big. Gabby Hayes big! (Vartiainen [2019: 909])

She explains that even if Gabby Hayes was quite a successful actor in Western movies, he could not be considered the typical example of a successful actor. This makes for the humorous conclusion of this cue, as the reader who knows the degree-proper name construction expects a typical example of success that would naturally confirm the statement that Milhouse is going to be "big", only to be stopped by the unexpected choice of the actor. They would have to think about how good an actor Gabby Hayes is, before concluding that since it is not the most natural choice, the foregone conclusion that Milhouse is going to be successful must be reassessed. In that particular example, Gabby Hayes is an incongruous choice of degree-proper name, which is due to his referent not being a paragon [2019: 909].

A paragon is the typical representative of a "type of thing". Al Capone, for instance, could be the paragon of gangsters, Hercules that of strong men, Versailles that of luxurious places. A paragon typically exceeds the quality that they represent: being a superlative is not so far from being an exaggerated version of some property. Proper 
names excel at creating paragons, especially in the context of antonomasia: it's the Kentucky Derby of drugs; a vast Pacific of unemployment. But in order to be paragons, they have to perform two distinct operations: they have to filter out all properties of their referent but the one(s) they are supposed to embody perfectly, and they have to do so to the point that it becomes exaggerated. This is why Gary-Prieur [2001] observes that it is easier to create paragons by making use of characters from the Greek mythology, fiction and literature pre-dating realistic novels, as they still represent types that do not have many distinctive properties to begin with. Such a remark echoes Bergson's point that characters from comedies, rather than tragedies, have their names used to exemplify types, precisely because a tragic character has to be complex - torn between at least two sides - whereas comedies present types that come close to caricatures, which he defines as follows:

The art of the caricaturist consists in detecting this, at times, imperceptible tendency, and in rendering it visible to all eyes by magnifying it. He makes his models grimace, as they would do themselves if they went to the end of their tether. (Bergson [1911: 10b])

41 The writer who uses a proper name as a degree-modifier, in antonomasia, or even in creating nicknames, is a kind of caricaturist. Note that what is really humorous according to Bergson is the process of making it visible, the ongoing exaggeration, rather than the well-known rigid figure of a typical character. This is probably why live antonomasia, rather than lexicalized antonomasia, is a greater source of humor, as it still enables the reader to compare the original referent with the model and to find their shared property without being told which one it is immediately (Leroy [2001: 301-303]).

Proper names also have the added property of solidifying that exaggeration. Nicknames may start as a caricature, but they can quickly become the only identity available for the referent, which becomes stuck in an archetypal version of itself.

(16) The police officers were sitting on the sofa in the living room, a fortysomething man in plain clothes and a younger one in uniform with acne on his neck. [...] He told me the other officer's name as well, but I don't remember it. I wasn't concentrating. [...] "I need to sit down," I said, and the detective motioned for me to take his place on the sofa, next to Neck Acne. [...] Neck Acne had a notebook out, pencil raised. I could hear the scratch of Neck Acne's pencil on paper, I could hear the blood pounding in my ears. [...] He glanced over at Neck Acne, then back at me. [several hundred pages down] They went away and left me there, with a uniformed officer-the one with the neck acne who came to Cathy's flat in Ashbury a lifetime ago-standing at the door, avoiding my eye. (Hawkins [2016: 99-103, 404])

In a very stressful, humor-deprived situation, the narrator in this excerpt cannot help but notice a distracting feature of one of her interlocutors. She fixates on it and soon creates a nickname that quickly replaces the official name of that police officer and becomes the only way she refers to him, or even thinks of him when she sees him again months later (end of the quote). A thorough discussion of the relationship between proper names, degree and categorization would require more space than a passing remark in this article, but I would like to suggest the following idea: proper names, being lexicalized units, can only rigidify some features of their initial referent when they adopt a common noun-like semantic profile; instead of the complex set of properties they can derive from their referent when they still have an associative kind of meaning, proper names behaving like common nouns see their meaning become more "predicative" or "descriptive", in the sense that a definition / description can 
now be attached to the proper name, and this definition is necessarily short(ened) and restricted to only a few properties of the initial referent. This process is not humorous in itself, but it can be used to explain why non-neutral nicknaming (Section 2) is perceived as humorous. If the nickname was motivated at first, then the proper name will retain the connection between the referent and its described property for as long as it is deemed relevant in context. Because of the naming convention between a proper name and its referent, even disparaging naming becomes the only way to refer to a referent, and lexicalization coupled with selection of / reduction to the relevant features will imprison it in the role of an unwilling paragon of sorts (the future exMr Mom for one man in the series of men that the writer's mom dates during his youth, Cowboy Cam for another step-father who is only known through his occupation because no other (personal) feature was deemed relevant enough, etc.). Once again, a scriptoriented interpretation of this humorous process would require metalinguistic scripts such as "suitable typification by proper name - not suitable typification by proper name".

\section{Conclusion}

Throughout this paper, I have tried to show how proper names could be analyzed as humorous devices using the framework of incongruity resolution theory, particularly drawing on the Bergsonian theory of rigidification. Proper names make use of their rigid lexical format to highlight any minor change to their form or meaning in context and exaggerate its consequences on the overall meaning of the sentence or on the resulting status of the proper name. Because they are rigid, proper names do not allow near synonyms or near homonyms to replace one of their parts, but they may be used as near homonyms to common nouns in order to alter the meaning of more flexible lexical patterns. Their high degree of lexicalization also tends to amplify any of its referent's properties that become associated with it, so that they soon become caricatural. In order to be understood as humorous, they often need to have other elements in the near context that will repeat or signal the property that the reader should select with respect to the proper name's referent. I thus believe that proper names do illustrate the traits of rigidification, repetition and exaggeration that characterize humor in Bergson's account and allow for the creation of metalinguistic opposition scripts in the framework of incongruity resolution theory, of which I have suggested a few throughout this paper.

\section{BIBLIOGRAPHY}

ANTONOPOULOU Eleni, 2004, "Humor Theory and Translation Research: Proper Names in Humorous Discourse", Humor - International Journal of Humor Research, n¹7 (3), 219-255. 
APTER Michael J. \& SMITH K. C. P., 1977, "Humor and the Theory of Psychological Reversals", in CHAPMAN Antony J. \& Foot Hugh C. (Eds.), It's a Funny Thing, Humor, Oxford, New York: Pergamon Press, 95-100.

ATTARDO Salvatore, 1994, Linguistic Theories of Humor. Humor Research 1, Berlin-New York: Mouton De Gruyter.

ATTARDO Salvatore (Ed.), 2014, Encyclopedia of Humor Studies, Thousand Oaks: SAGE Publications. BALTEIRO Isabel \& BAUER Laurie (Eds.), 2019, Blending in English, Lexis nº 14.

BERGSON Henri, 1911, An Essay on the Meaning of the Comic, translated from the French by Cloudesley Brereton \& Fred Rothwell, London: Macmillan.

BOLINGER Dwight, 1972, Degree Words, The Hague-Paris: De Gruyter Mouton.

BREBAN Tine, 2018, "Proper Names Used as Modifiers: A Comprehensive Functional Analysis", English Language and Linguistics $\mathrm{n}^{\circ} 22$ (3), 381-401.

BRINTON Laurel \& TRAUGOTT Elizabeth, 2005, Lexicalization and Language Change, Research Surveys in Linguistics, Cambridge: Cambridge University Press.

CALEFFI Paola-Maria, 2015, “The hashtag”: A New Word or a New Rule?", Skase Journal of Theoretical Linguistics, $\mathrm{n}^{\circ} 12$ (2), 46-69.

CHIARo Delia, 2017, The Language of Jokes in the Digital Age. Viral Humor, Abingdon: Routledge. DE COCK Barbara\& PIZARRO PEDRAZA Andrea, 2016, "Reinterpreting the Use of Hashtags: The Humoristic Use of \#jesuis", $4^{\text {th }}$ International, Interdisciplinary Symposium: Microanalysis of Online Data (MOOD-S), Salford.

DYNEL Marta, 2014, "Linguistic Approaches to (Non)Humorous Irony", HUMOR, n²7 (4), 537-550.

EDWARDS Gavin, 1996, “William Hazlitt and the Case of the Initial Letter”, Text n9, 260-279.

FAUCONNIER Gilles, 1975, “Pragmatic Scales and Logical Structure”, Linguistic Inquiry Vol. 6 (3), 353$375:$ https://www.jstor.org/stable/4177882

FORABOSCO Giovannantonio, 2008, "Is the Concept of Incongruity Still a Useful Construct for the Advancement of Humor Research?”, Lodz Papers in Pragmatics nº (1), 45-62.

GARY-PRIEUR Marie-Noëlle, 1991, « Le nom propre constitue-t-il une catégorie linguistique ?», Langue française $\mathrm{n}^{\circ} 92$ (1), 4-25.

GARY-PRIEUR Marie-Noëlle, 2001, L'individu Pluriel : Les Noms Propres et Le Nombre, Sciences Du Langage, Paris: CNRS éditions.

GIORA Rachel, 2002, “Optimal Innovation and Pleasure', in STOCK Oliviero, STRAPPARAVA Carlo \& NIJHOLT Anton (Eds.), TWLD20 - The April Fools' Day Workshop on Computation Humor, Trento, 11-28. GRAPHÈMES, 2010 (November), ‘Des Minuscules Sinon Rien', La Pause Design 41.

HANDLER Peter, 2018, « Les noms de domaine - une nouvelle source de créativité langagière », in WinTER-Froemel Esme \& DemeulenAere Alex (Eds.), Jeux de mots, textes et contextes, Amsterdam: De Gruyter, 289-314.

KERBRAT-ORECCHIONI Catherine, 1977, La Connotation, Linguistique et Sémiologie, Lyon : Presses universitaires de Lyon.

KRIPKE Saul, 1980, Naming and Necessity, Cambridge, Mass: Harvard University Press. 
KUIPER Koenraad, 2007, "Cathy Wilcox Meets the Phrasal Lexicon. Creative Deformation of Phrasal Lexical Items for Humorous Effect", in MuNAT Judith (Ed.), Lexical Creativity, Texts and Contexts, n58, Amsterdam, Philadelphia: John Benjamins, 93-112.

KUNNEMAN Florian, LIEBRECHT Christine, VAN MULKEN Margot \& VAN DEN BOSCH Antal, 2015, "Signaling Sarcasm: From Hyperbole to Hashtag", Information Processing \& Management n 51 (4), 500-509.

LAWRENCE Emilie \& RINGROSE Jessica, 2018, “@NoToFeminism, \#FeministsAreUgly and Misandry Memes: How Social Media Feminist Humor Is Calling out Antifeminism", in Keller Jessalynn \& RYAN Maureen E., Emergent Feminisms: Complicating a Postfeminist Media Culture, New York: Routledge, 211-232.

LEHRER Adrienne, 2007, “Blendalicious”, in MUNAT Judith (Ed.), Lexical Creativity, Texts and Contexts, n58, Amsterdam, Philadelphia: John Benjamins, 115-133.

LEROY Sarah, 2001 Entre Identification et Catégorisation, l'antonomase du Nom Propre en Français, Thèse de doctorat, Université Paul Valéry-Montpellier 3.

LUNDE Ingunn, 2016, "Hashtag Poetics: Political Humor on Russian Twitter”, Zeitschrift Für Slawistik $n^{\circ} 61(1), 102-118$.

MARIAULE Mickaël, 2008, La traduction du jeu de mots dans les titres de presse, in Équivalences $n^{\circ} 35$ (1-2), Jeux de mots et traduction, 47-70, https://www.persee.fr/doc/

equiv_0751-9532_2008_num_35_1_1430

MARTIN Rod A., 2010, The Psychology of Humor: An Integrative Approach, Educational Psychology, Amsterdam: Elsevier.

MILL John Stuart, 1960 [1843], A System of Logic: Ratiocinative and Inductive, Abingdon: Routledge.

MULDER Marijn P. \& Nijholt Antinus, 2002, “Humor Research: State of the Art”, CTIT Technical Report Series $\mathrm{n}^{\circ} 2$ (34), Twente, 1-24.

MUNAT Judith, 2007, "Lexical Creativity as a Marker of Style in science fiction and children's literature", in MUNAT, Judith (Ed.), Lexical Creativity, Texts and Contexts, $\mathrm{n}^{\circ} 58$, Studies in Functional and Structural Linguistics, Amsterdam, Philadelphia: John Benjamins, 163-185.

PARADIS Carita, 2000, “It's Well Weird. Degree Modifiers of Adjectives Revisited: The Nineties”, in KIRK John M. (Ed.), Corpora galore: analyses and techniques in describing English, Amsterdam: Rodopi, 147-160.

PHILIPPE Manon, 2020, Le Nominal Propre. Étude Du Nom Propre En Anglais, Thèse de doctorat, Paris: Sorbonne Université.

PHILIPPE Manon, 2021, "Proper Names and the "Noun" / "Name" Categories: Pseudo-Nouns, Real Names", Proceedings of the International symposium on the NOUN / NAME. 28-29-30 March 2019 (submitted)

POPESCU Carmen, 2003, “Theories of Humor”, Revue Roumaine de Linguistique n48 (1-4), 187-192.

RABATEL Alain, 2011a, « Figures d'à-peu-près et Nom propre », Le Français Moderne - Revue de linguistique Française ${ }^{\circ} 79$ (1), 22-23, http://www.le-francais-moderne.com/pages/archivesfm.html

RABATEL Alain, 2011b, « Pour une analyse pragma-énonciative des figures de l'à-peu-près ", Le Français Moderne - Revue de linguistique Française n79 (1), 1-9, http://www.le-francaismoderne.com/pages/archives-fm.html 
RAYNAUD Jean, 1977, « Des mécanismes du jeu de mots », Revue française d'études américaines $n^{\circ} 4$, 23-30.

RENNER Vincent, 2015, “Lexical Blending as Wordplay”, in ZIRKER Angelika \& WINTER-FroEMEL Esme, Wordplay and Metalinguistic / Metadiscursive Reflection, Amsterdam: De Gruyter, 119-134.

RUCHON Catherine, 2018, « Le jeu de mots dans les discours sur le deuil : un jeu discursif offensif », in Winter-Froemel Esme \& Demeulenaere Alex (Eds.), Jeux de mots, textes et contextes, Amsterdam: De Gruyter, 135-156.

RUTKOWSKI Mariusz, 2016, "Humorous Names in the Light of Incongruity Theory", воПРосы онОМАСТИКИ ${ }^{\circ} 13$ (1), 129-139.

STOCK Oliviero, STRAPPARAVA Carlo, 2002, "Humorous Agent for Humorous Acronyms: The HAHAcronym Project”, in STock Oliviero, StRAPPARAVA Carlo \& NijHolt Anton (Eds.), TWLD20 - The April Fools' Day Workshop on Computation Humor, Trente, 125-136.

STRAZNY Philipp (Ed.), 2011 (2004), Encyclopedia of Linguistics, Vol. 1-2, New York: Routledge Taylor \& Francis e-Library.

SULLET-NYLANDER Françoise, 2018, «Jeux de mots à la Une d'hier et d'aujourd'hui : dynamique et diversité d'un genre ", in WinTER-Froemel Esme \& DEMEULENAERE Alex (Eds.), Jeux de mots, textes et contextes, Amsterdam: De Gruyter, 241-264.

TABACARU Sabina \& LEMMENS Maarten, 2014, 'Raised Eyebrows as Gestural Triggers in Humor: The Case of Sarcasm and Hyper-Understanding”, European Journal of Humor Research, n² (2), 11-31.

VARTIAINEN Turo, 2019, “From Twig-Skinny to Kate Moss Skinny: Expressing Degree with Common and Proper Nouns", English Language and Linguistics n²3 (4), 901-927.

VEALE Tony, 2004, “Incongruity in Humor: Root Cause or Epiphenomenon?", Humor - International Journal of Humor Research $n^{\circ} 17$ (4), 419-428.

VEATCH Thomas C., 1998, “A Theory of Humor”, Humor - International Journal of Humor Research n¹1 (2), 161-215.

WARREN Caleb \& MCGRAW A. Peter, 2016, "Differentiating What Is Humorous from What Is Not", Journal of Personality and Social Psychology n¹10 (3), 407-430.

ZAPPAVIGNA Michele, 2018, Searchable Talk: Hashtags and Social Media Metadiscourse, London: Bloomsbury Academic.

Personal examples from my own corpus:

COCHRANE Lauren, 2017, “No-Drama Garms - How Men's Fashion Came down to Earth”, The Guardian, 10 January 2017, Culture. www.theguardian.com/fashion/2017/jan/10/london-fashionweek-no-drama-garms-how-menswear-came-down-to-earth-.

DESMOND Matthew, 2016, Evicted: Poverty and Profit in the American City. EPub, London: Penguin Books.

HAWKINS Paula, 2016. The Girl on the Train, London: Black Swan.

HERITAGE Stuart, 2017, "Forget Bins, Immigrants Need to Know the Difference between Tea and Supper”, The Guardian, 10 January 2017, Opinion. www.theguardian.com/commentisfree/2017/ jan/10/forget-bins-immigrants-need-to-know-the-difference-between-tea-and-supper.

ST AUBYN Edward, 2015, Lost for Words, London: Picador. 
THOMPSON Nigel, 2017, "Why you'll be blown away by the Windy City", Mirror online, 6 February 2017, Travel. www.mirror.co.uk/lifestyle/travel/usa-long-haul/youll-blown-away-seventhings-9738425.

VANCE James David, 2016, Hillbilly Elegy: A Memoir of a Family and Culture in Crisis, EPub. New York: Harper Collins.

\section{NOTES}

1. Giora uses departures from the expression Body and soul and subjects' judgments of humor to determine what is optimally innovative / humorous: the plural form Bodies and souls was deemed too familiar to be humorous, the paronymic proper names Bobby and Saul too creative, but the expression body and sole (with the homophone for "soul" the only departure from the original expression) was deemed humorous and therefore optimally innovative.

2. This effort need not be translated into a longer reading time. Names of domains in website addresses - which have been compared and, in some cases, assimilated to brand names and slogans (Handler [2018:295]) - may take part in humorous productions involving lexical creativity, but they do not hamper reading and processing as long as they are short. Wordplay is also associated, in Freud's theory of humorous economy of words and condensation of thoughts, with the economy of psychic release involved in processing the playful production (Ruchon [2018]).

\section{ABSTRACTS}

This paper analyses how proper names fit in the incongruity resolution theory of humor, more specifically Bergson (1911)'s theory of humor as rigidification (and related distraction and exaggeration). The relevant properties of proper names, such as their rigid format and semantic unanalysability, their high degree of lexicalization, and their potential role as parangons, are explained in order to suggest possible metalinguistic script oppositions that could describe how proper names, as lexical units, are used in humorous contexts.

Cet article s'intéresse aux liens entre les noms propres en anglais et les théories de l'humour fondées sur l'incongruité et sa résolution, en particulier la théorie bergsonienne de la raideur mécanique et des phénomènes adjacents de distraction et exagération (1911). Le figement morphosyntaxique des noms propres, leur impossible analyse sémantique, leur haut degré de lexicalisation et leur capacité à devenir des parangons sont étudiés afin de faire émerger de potentielles oppositions de scripts expliquant comment les noms propres, en tant qu'unités lexicales, favorisent la production d'un humour reposant sur des bases métalinguistiques.

\section{INDEX}

Keywords: proper names, incongruity, metalinguistic properties, Bergson, humor

Mots-clés: noms propres, incongruité, métalinguistique, Bergson, humour 
AUTHOR

MANON PHILIPPE

Sorbonne Université

manon.philippe@sorbonne-universite.fr 